\title{
SSynthesis
}

International Scientific Conference of IT and Business-Related Research

\section{PROBLEMATIČNI KREDITI STANOVNIŠTVA U SRBIJI}

\section{NON - PERFORMING LOANS OF CITIZENS IN SERBIA}

\author{
Duško Ranisavljević ${ }^{1}$, Miroljub Hadžić ${ }^{2}$ \\ ${ }^{1}$ Marfin Bank A.D., Beograd, Srbija \\ ${ }^{2}$ Univerzitet Singidunum, Danijelova 32, Beograd, Srbija
}

\begin{abstract}
Apstrakt:
U periodu ekonomske recesije, primetan je rast vrednosti problematičnih kredita fizičkih lica (sa 22 na 34 milijarde RSD) i njihovog učešća u ukupnom portfoliju stanovništva poslovnih banaka u Srbiji (sa 4,4 na 6\%). U strukturi kreditnih proizvoda namenjenih stanovništvu sa kašnjenjem najviše prednjače gotovinski krediti, ali je poslednjih godina primetan trend porasta problematičnih kredita svih vrsta kredita stanovništvu. Razlozi za rast problematičnih kredita stanovništva su višestruki, prvenstveno smanjena kreditna sposobnost stanovništva, pad stope zaposlenosti, pad zarada, kao i liberalnija metodologija poslovnih banaka prilikom odobrenja kreditnih zahteva.

Porast problematičnih kredita i posebno problematičnih kredita stanovništva, predstavlja ozbiljnu pretnju stabilnosti bankarskog sektora u Srbiji, te je neophodno njihovo stalno podrobno praćenje, sveobuhvatno sistemsko rešenje radi efikasnijeg suzbijanja njihovog daljeg rasta, na makroekonomskom nivou, i preduzimanje mera rešavanja postojećeg portfolija problematičnih kredita na nivou pojedinačne banke, dakle, mikroekonomski.
\end{abstract}

\section{Ključne reči:}

krediti, problematični krediti, kreditni rizik, kreditna sposobnost.

\section{UVOD}

Svetska ekonomska kriza imala je negativne efekte na privredne subjekte i ekonomiju Srbije u celini, što je za posledicu imalo negativan uticaj na privrednu aktivnost, zaposlenost, životni standard građana i na kreditnu sposobnost fizičkih lica.

Smanjena kreditna sposobnost fizičkih lica uslovila je smanjenje tražnje za kreditima i otežanu sposobnost otplate postojećih kredita fizičkih lica. To je uslovilo rast problematičnih kredita u vrednosti ukupno odobrenih kredita i broj ovih klijenata u ukupnom broju zajmotražilaca poslovnih banaka.

$\mathrm{U}$ fokus analize u ovom radu su stavljeni krediti stanovništvu. Analizirani su pokazatelji za period od poslednjeg kvartala 2011. godine, zaključno sa trećim kvartalom 2014. godine, što je omogućilo utvrđivanje tendencija i donošenje zaključaka.

Osnovna hipoteza rada je da rast problematičnih kredita stanovništva i rast njihovog učešća u ukupnom kreditnom portfoliju stanovništva nije dramatičan, ali da zahteva preduzimanje mera u cilju zaustavljanja tendencije i obezbeđenja stabilnosti bankarskog sektora.

U radu će se najpre izvršiti analiza dinamike kretanja problematičnih potraživanja stanovništva, njihovog učešća u ukupnom portfoliju stanovništva i po strukturi vrsta kredita. Takođe će se pokušati utvrditi povezanost između njihovog rasta

\section{Abstract:}

During the period of recession, an increase in the value of non performing loans (NPLs), and their share in total credit portfolio of citizens can also be observed (from 22 to 34 billion RSD and from 4,4 to $6 \%$, respectively). Therefore, cash credits are the most problematic in the structure of credits intended for citizens. However, a growing trend in the number of all types of NPLs to citizens can be observed. There are numerous factors leading to the increase in non - performing loans of citizens, including the lower creditworthiness of citizens, growing unemployment rate, decreasing wages and more flexible banks' methodology for the approval of loan applications.

The increase in non-performing loans in general, and in particular, non-performing loans of citizens, is an important threat to the stability of the banking sector of Serbia. Therefore, it is important to permanently monitor them, to create macroeconomic solution to prevent their further growth and to take necessary measures at the level of each bank in order to successfully overcome the issue of NPLs.

\section{Key words:}

loans, non-performing loans, credit risk, creditworthiness.

i uzroka vezanih generalno za produženu recesiju i njene posledice. Na kraju će se, korišćenjem metode sinteze, formulisati mere za zaustavljanje tendencije rasta na makro i mikro nivou.

\section{PROBLEMATIČNI KREDITI I IZROCI}

Sumnjivi i nenaplativi krediti (Non-performing loans - NPL), u skladu sa međunarodno prihvaćenom definicijom, predstavljaju stanje duga plasmana koji su u docnji preko 90 dana ili sa docnjom ispod 90 dana, ukoliko banka proceni da je kreditna sposobnost dužnika toliko ugrožena, da se otplata duga u celosti, dovodi u pitanje (IMF, 2005). Procenat udela ovih kredita se može izražavati i kao racio broj, kao odnos problematičnih kredita i iznosa ukupnih kredita stanovništvu, po tipovima kredita, odnosno iznosa ukupnih kredita banke.

U tabeli 1 dat je kvartalni pregled iznosa problematičnih kredita stanovništvu (reatil) u Srbiji po vrstama kredita (Kvartalni izveštaji NBS-Bankarski sektor u Srbiji za period 2011-2014):

Najveći porast problematičnih kredita u navedenom periodu imali su gotovinski krediti 76,7\%, dok je ukupni problematični portfolio retail kredita porastao za $57,2 \%$. Značajan je i porast docnje u izmirenju overdrafta $u$ posmatranom periodu, koja je porasla $50 \%$. 


\begin{tabular}{|c|c|c|c|c|c|c|c|}
\hline & 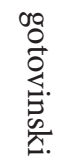 & 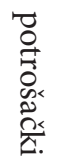 & 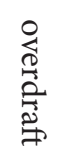 & 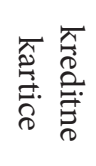 & $\begin{array}{l}\text { Problematični retail } \\
\text { krediti ukupno } \\
\text { (mlrd RSD) }\end{array}$ & $\begin{array}{l}\text { Krediti stanovništva } \\
\text { ukupno (mlrd RSD) }\end{array}$ & $\begin{array}{l}\text { Udeo problematičnih } \\
\text { retail kredita u } \\
\text { ukupnim kreditima } \\
\text { stanovništva }\end{array}$ \\
\hline 31.12 .11 & 11,6 & 3,1 & 2,8 & 4,0 & 21,5 & 493 & $4,36 \%$ \\
\hline 31.03 .12 & 12,8 & 2,6 & 3,3 & 4,2 & 22,9 & 515 & $4,47 \%$ \\
\hline 30.06 .12 & 13,5 & 2,7 & 3,4 & 4,4 & 24,0 & 534 & $4,49 \%$ \\
\hline 30.09 .12 & 15,0 & 3,0 & 3,5 & 4,7 & 26,2 & 539 & $4,86 \%$ \\
\hline 31.12 .12 & 15,0 & 3,0 & 3,5 & 4,6 & 26,1 & 532 & $4,91 \%$ \\
\hline 31.03 .13 & 15,2 & 3,2 & 3,7 & 4,8 & 26,9 & 527 & $5,10 \%$ \\
\hline 30.06 .13 & 16,2 & 3,4 & 3,8 & 5,0 & 28,4 & 543 & $5,23 \%$ \\
\hline 30.09 .13 & 16,7 & 3,5 & 3,9 & 5,1 & 29,2 & 552 & $5,29 \%$ \\
\hline 31.12 .13 & 18,3 & 3,5 & 3,9 & 5,1 & 30,8 & 549 & $5,61 \%$ \\
\hline 31.03 .14 & 19,1 & 3,5 & 4,0 & 5,1 & 31,7 & 551 & $5,75 \%$ \\
\hline 30.06 .14 & 20,4 & 3,6 & 4,2 & 5,5 & 33,7 & 561 & $6,01 \%$ \\
\hline 30.09 .14 & 20,5 & 3,6 & 4,2 & 5,5 & 33,8 & 580 & $5,83 \%$ \\
\hline
\end{tabular}

Tabela 1. Problematični krediti stanovništva po kreditnim proizvodima

Izvor: NBS - Kvartalni izveštaji 2011-2014.

Udeo problematičnih retail kredita u ukupnom portfoliju kredita imao je takođe trend rasta. Treba imati u vidu da u retail kredite u kašnjenju, ne ubrajamo stambene, auto i kredite poljoprivrednim proizvođačima, inače bi taj procenat bio značajno veći. Retail kreditni proizvodi ročnosti od jedne do osam godina, i nisu većeg iznosa, najčešće do iznosa dinarske protivvrednosti 10 hiljada $€$, zavisno od instrumenata obezbeđenja. Krajem 2014. godine iznos problematičnih retail kredita je iznosio oko 6\% ukupnog kreditnog portfolija fizičkih lica.

U grafikonima 1 i 2, dat je prikaz kretanja kredita u kašnjenju po vrstma, i uporedni trend problematičnih retail kredita sa trendom ukupnih kredita stanovništvu.

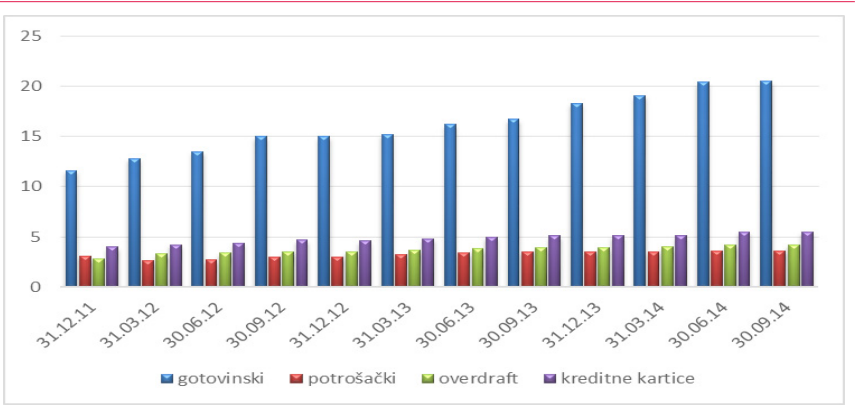

Grafikon 1. Problematični krediti stanovništva po vrstama, mlrd RSD 2011-14.

Izvor: Kvartalni izveštaji NBS- Bankarski sektor u Srbiji, za period 2011-2014.

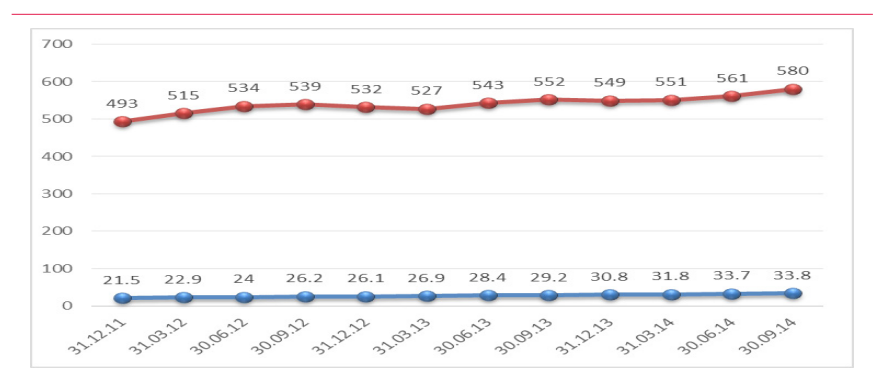

Grafikon 2. NPL retail kredita i ukupni krediti stanovništva u mlrd RSD, 2011-14.

Izvor: Kvartalni izveštaji NBS- Bankarski sektor u Srbiji, za period 2011-2014
Razlozi koji su se u praksi pokazali kao najvažniji za uvećanje NPL-a kredita fizičkih lica su: metodologija obračuna kreditne sposobnosti fizičkih lica od strane banaka, promene deviznog kursa, povećanje nezaposlenosti, stagnacija i pad prosečne zarade i nestabilnost u poslovanju poslodavaca dužnika.

Metodologija obračuna kreditne sposobnosti je skup pravila i politika kojima banka definiše kriterijume i način odobrenja kreditnog aranžmana. Okvir za kriterijume odobrenja, propisan je kroz Odluku o klasifikaciji bilansne aktive i vanbilansnih stavki poslovnih banaka (NBS, 2014). Osnovni kriterijum koji fizičko lice mora zadovoljiti je adekvatnost DTI racia (Debt to income), koji predstavlja odnos kreditnih obaveza prema mesečnim prilivima. U poslednjih deset godina, propisani iznos maksimalnog DTI racia se menjao, od $30 \%$, potom $40 \%$, da bi od početka 2013. godine, u većini banaka u Srbiji on iznosio 50-60\% opterećenja mesečne zarade (za dinarska kreditna zaduženja). To znači, da se za samo nekoliko godina maksimalni dozvoljeni procenat opterećenja mesečne plate/penzije, praktično udvostručio, a da to nije praćeno pozitivnim ekonomskim trendovima, naprotiv. Metodologija poslovnih banaka koja dozvoljava opterećenje mesečnih primanja do 60\% (bez uračunavanja minimalne potrošačke korpe, ili bez ikakvog drugog ograničenja), može fizička lica sa nižim nivoom prihoda dovesti u situaciju da se samim odobrenjem kredita generišu finansijske poteškoće i otežana otplata. Drugim rečima, primena ovakve metodologije potencijalno povećava kreditni rizik. Na primer, fizička lica sa primanjima od 22-30.000 RSD (ili penzioneri sa nižim primanjima), ako se opterete sa navedenim procentom kreditnog zaduženja, preostala sredstva za život, svakako neće biti dovoljna, te se vrlo brzo, mogu očekivati problemi u otplati. Ova fizička lica će zbog primene ovakve metodologije obračuna kreditne sposobnosti doći u situaciju da biraju, da li da inače mala primanja, rasporede na nužnu potrošnju ili na ratu kredita. Realno je da će u kratkom roku prevagnuti prva opcija, te će takav kredit neminovno dospeti u docnju. Ovakvo prilagođavanje metodologije može se razumeti tako da poslovne banke ostvare dobre poslovne rezultate na kratak rok, da uvećaju svoje plasmane i da i na taj način umanje učešće NPL zbog povećanog kreditnog portfolija.

Promene deviznog kursa i odnosa valuta (devizni rizik) mogu takođe biti generator otežane otplate, ukoliko je kreditni aranžman indeksiran u ino valuti. Upravo zbog mogućeg 
deviznog rizika poslednjih godina kreditni proizvodi stanovništvu su u niskom procentu indeksirani u ino valuti. Tome je i doprinela obaveza polaganja depozita ili učešća prilikom odobrenja kredita indeksiranih $\mathrm{u}$ ino valuti (prema navedenoj regulativi). Prema podacima NBS (III kvartal, Bankarski sektor u Srbiji, 2014), na dan 30.09.2014. godine, 60\% svih kreditnih zajmova u Srbiji indeksirano je u valuti EUR, u valuti CHF 6\%, dok je dinarskih kredita 30\%. Ako su kreditni proizvodi fizičkih lica vezani za ino valutu, teže se otplaćuju ukoliko postoji valutna neusklađenost između valute plate (primanja) i valute indeksacije kredita. Kako je većina kredita sa valutnom indeksacijom indeksirana u valuti EUR, a većina korisnika kredita nema valutnu indeksaciju u primanja, procenat rasta deviznog kursa, neminovno implicira proporcionalno uvećanje obaveza po kreditu. Poseban problem su krediti indeksirani u CHF, jer je ova valuta ostvarila vrlo visok rast u odnosu na druge valute, naročito poslednjih godina, što je korisnike takvih kredita dovelo u nezavidnu situaciju. Treba napomenuti da se problem otplate ovih kredita, uglavnom svodi na stambene kredite.

Porast nezaposlenosti, a naročito pad zaposlenosti ima direktan uticaj na povećanje NPL-a. Gubitak posla, bez pronalaženja novog zaposlenja, onemogućava fizičko lice da izmiruje kreditne obaveze, jer ne postoje redovni izvori za tu namenu. Prema zvaničnim podacima za populaciju od 15-64 godine u Srbiji, na kraju 2014. godine, nezaposlenost u Srbiji je iznosila 17,6\% (Republički zavod za statistiku, 2014). Postoji bojazan da je realna nezaposlenost veća. Pojedine banke su predupredile ovaj rizik, tako što prilikom odobrenja kredita, kreditni aranžman osiguravaju, tačnije osiguravaju korisnika kredita, da u slučaju gubitka posla, kreditne obaveze izmiri osiguravajuća kuća. Ovo solucija svakako dodatno poskupljuje inicijalni kreditni aranžman, ali se ipak na taj način anulira veoma važan i, $u$ vreme ekonomske krize veoma prisutan rizik.

Stagnacija i pad realnih zarada predstavlja osnovu za umanjenje kreditne sposobnosti i otežanu otplatu kreditnih zajmova. Prema zvaničnim podacima prosečna zarada u Republici Srbiji isplaćena u decembru 2014. godine manja je u odnosu na prosečnu zaradu iz decembra 2013. godine nominalno 1,9\%, a realno za 3,5\% (Republički zavod za statistiku, 2015). Vlada Republike Srbije je krajem 2014. godine započela sprovođenje mera štednje u javnom sektoru, koje podrazumevaju smanjenje zarada u javnom sektoru za oko $10 \%$, penzija takođe, što znači da je delu korisnika kredita od početka 2015. godine otplata kreditnih zajmova otežana, što će se odraziti u ovoj i narednim godinama. U momentu odobrenja, ni poslovne banke ni klijenti nisu mogli očekivati ovu meru. Valja imati u vidu da su za poslovne banke u Srbiji, naročito u segmentu stanovništva posebno interesantni klijenti zaposleni u javnom sektoru, kao i penzioneri, zbog stabilnosti primanja.

Stabilno poslovanje poslodavca podrazumeva stabilnu finansijsku situaciju poslodavca, njegovu likvidnost, sposobnost i urednost izmirenja obaveza prema zaposlenima. Zbog narušene likvidnosti, poslovni računi mnogih poslodavaca su često blokirani, pa dolazi do kašnjenja u isplati zarada, što implicira i kašnjenja u otplati kredita, time i pogoršanje klasifikacione oznake klijenta fizičkog lica i veći trošak rezervacije. Pretpostavlja se da je skoro polovina privrednih subjekata u Srbiji manje ili više nelikvidna, a da se na šest novoosnovanih ugasi čak deset preduzeća. Poslednjih godina nisu retki slučajevi u praksi, da je ugroženo poslovanje, ne samo poslodavaca firmi u privatnom vlasništvu, već i poslodavaca javnih preduzeća i državnih institucija, što direktno generiše smanjenu kreditnu sposobnost zaposlenih. Sudeći prema najavama jedna četvrtina zaposlenih u javnom sektoru je zapravo višak, te se može na srednji rok očekivati dalje smanjenje zaposlenosti.
Smanjenje kreditne sposobnosti predstavlja posledicu više negativnih efekata ekonomske recesije, kroz koju Srbija prolazi i oni se manifestuju kroz pad zaposlenosti, pad realnih zarada, povećanje troškovi života i sl. U Tabeli 2. dati su podaci o broju zaposlenih i iznosu problematičnih kredita stanovništvu, ukupno, za kvartale 2013/14.

\begin{tabular}{|c|c|c|}
\hline Kvartali 2013/2014 & $\begin{array}{c}\text { Broj zaposlenih (u } \\
000)\end{array}$ & $\begin{array}{c}\text { Problematični retail } \\
\text { krediti (ukupno u } \\
\text { mlrd RSD) }\end{array}$ \\
\hline 31.03 .2013 & 1.725 & 26.9 \\
\hline 30.06 .2013 & 1.718 & 28.4 \\
\hline 30.09 .2013 & 1.705 & 29.2 \\
\hline 31.12 .2013 & 1.703 & 30.9 \\
\hline 31.03 .2014 & 1.690 & 31.7 \\
\hline 30.06 .2014 & 1.704 & 33.7 \\
\hline
\end{tabular}

Tabela 2. Zaposlenost i problematični krediti

Izvor: Republički zavod za statistiku, Statistički bilten 2014, Narodna banka Srbije, Kvartalni izveštaji 2013/14)

Zaposlenost je jedan od osnovnih kriterijuma kreditne sposobnosti i faktor uredne otplate kredita, pa je iz tog razloga uzet kao parametar za analizu. Pearsonov koeficijent korelacije (xbroj zaposlenih, $y$-problematični krediti u retail kreditnom segmentu) u ovom slučaju iznosi: $r=-0,765$. Na osnovu visoke negativne vrednosti koeficijenta može se zaključiti da je potvrđena visoka negativna korelacija između promene broja zaposlenih i povećanja iznosa problematičnih kredita. Naime, dobijeni koeficijent korelacije je blizu referentne vrednosti (-1). Smanjenje broja zaposlenih, očigledno je u direktnoj vezi sa povećanjem iznosa problematičnih kredita u retail kreditnom segmentu.

\section{MERE ZA SMANJENJE PROBLEMATIČNIH KREDITA}

Polazeći od navedene definicije problematičnih kredita, učešće NPL u ukupnim se može umanjiti na dva načina:

- povećanjem ukupnog kreditnog portfolija;

- suzbijanjem - smanjenjem iznosa problematičnih kredita.

Prvi način podrazumeva smanjenje NPL-a na način, tako da se nivo ukupnih kredita povećava, i to kroz odobrenje novih kredita. Nivo ukupnih kredita je imenilac u odnosu, kojim se dobija procenat NPL-a, pa uvećanje imenioca smanjuje dobijeni odnos tj. procenat NPL-a. Povećanje ukupnog kreditnog portfolija, podrazumeva povećanu kreditnu aktivnost, s tim što se mora uzeti u obzir kreditni rizik, i mogućnost da i novoodobreni krediti mogu, u određenom vremenskom periodu i sami postati problematični krediti i time uvećati NPL. Prilagođavanje metodologije obračuna kreditne sposobnosti, u navedenim okolnostima, predstavlja „podizanje praga“ kreditne sposobnosti fizičkih lica. To znači da poslovne banke u takvim okolnostima odobravaju kreditne proizvode klijentima kojima u prethodnom periodu ne bi odobravali takve ili bilo kakve kreditne aranžmane. Upravo je u radu problematizovan ovaj pristup, jer su domaće banke svesno pristupile labavljenju kriterijuma za odobravanje kredita stanovništvu izmenama metodologije, na taj način veštački povećavajući kreditnu sposobnost klijenata.

Povećanje kreditne aktivnost i kreditnog portfolija u periodu ekonomske recesije nije jednostavan zadatak, kako zbog smanjenje tražnje za kreditima, tako zbog umanjene kreditne sposobnosti klijenata. Pojedine poslovne banke, da bi stimuli- 
sale tražnju za kreditima i da bi se prilagodile umanjenoj kreditnoj sposobnosti klijenata, svoju poslovnu politiku prilagođavaju takvim, novim okolnostima. Prilagođavanje poslovne politike podrazumeva da banke snize kamate i naknade svojih kredita, učine ih tržišno atraktivnijim i tako ih promovišu postojećim i novim klijentima. To podrazumeva smanjenje kamatne marže, i tada se cena kreditnog proizvoda ne formira u skladu sa kretanjem kreditnih izvora, već sa ciljem da kamatna stopa bude prihvatljiva većem broju klijenata, iako to negativno utiče na profitabilnost kreditnog proizvoda. Posebno treba naglasiti, da se ovakve aktivnosti rade upravo u periodu ekonomske recesije, koja po prirodi generiše nešto veći kreditni rizik, što bi naprotiv uslovilo politiku povećanja kamatnih stopa. Atraktivnijim kreditnim proizvodima i fleksibilnijom metodologijom obračuna kreditne sposobnosti, banke u Srbiji na kratak rok, uvećavaju kreditni portfolio fizičkih lica, što u tom periodu umanjuje procenat NPL-a.

Drugi pristup predstavlja aktivnosti banke na smanjenju problematičnih kredita. Smanjenje kredita u kašnjenju predstavlja aktivnosti, koje imaju za cilj da se konkretni problematični plasmani reše. Suština je u pravovremenom i brzom reagovanju i preduzimanju konstruktivnih postupaka (Rouse, 2002). Praktično, to podrazumeva sledeće aktivnosti: restruktuiranje problematičnih kredita, aktiviranje instrumenata obezbeđenja u cilju naplate i/ili ustupanje kreditnog potraživanja banke.

Restruktuiranje kredita je jedan od najzastupljenijih načina da se problematični krediti dovedu u urednu otplatu. Krediti za restruktuiranje omogućavaju da se kreditne obaveze dužnika fizičkog lica, grupišu u jedan kreditni aranžman, obično dužeg roka dospeća što omogućava, niže mesečne obaveze i lakšu otplatu kreditne obaveze. Obično se za kredit za restruktuiranje traži dodatno obezbeđenje (žirant, zaloga, jemstvo i sl.), iz razloga povećanog kreditnog rizika. Restruktuiranje se radi i kada dođe do prezaduženosti klijenata fizičkih lica. Raspoloživost potrošačkih kredita, veliki asortiman roba koje se mogu kupiti na kredit, želja za većim životnim standardom, agresivne marketing strategije i netransparentnost kreditnog tržišta, utiču na svest potrošača i ohrabruju ih da se zadužuju i kada nisu platežno sposobni i nisu otplatili prethodno odobrene kredite (Jovanić, 2004).

Ukoliko je nemoguće sprovesti restruktuiranje kreditnih zaduženja fizičkog lica, banke su prinuđene da iniciraju sudski spor i aktiviraju instrumente obezbeđenja. Nemogućnost restruktuiranja se ogleda u evidentno narušenoj kreditnoj sposobnosti, ili proceni banke da postoji visok operativni, devizni rizik ili drugi rizik. Postoje instrumenti obezbeđenja koji mogu biti aktivirani (koji su naplativi) i pre utuženja klijenta (na primer namenski depozit), dok je za aktiviranje ostalih instrumenata obezbeđenja, neophodno utuženje fizičkog lica. Iniciranjem sudskog spora, čemu prethodi proglašenje kreditnog aranžmana dospelim, ukupno potraživanje banke po takvim kreditnim aranžmanima se značajno uvećava (zatezna kamata, sudski troškovi, itd.). Realizacija instrumenata obezbeđenja može trajati duži vremenski period, a naročito u slučaju založnog prava na nepokretnosti, tako da poslovne banke moraju posebno voditi računa o naplativosti (utrživosti) kreditnih obezbeđenja (kolaterala) prilikom odobrenja kredita.

Kao treći način, umanjenja problematičnih kredita, može se vršiti ustupanje potraživanja drugim finansijskim institucijama, što je u skladu sa Zakonom o zaštiti korisnika finansijskih usluga. U Srbiji je moguće potraživanja poslovnih banaka po osnovu kredita fizičkim licima, za razliku od pravnih lica, ustupiti samo drugim finansijskim institucijama, ne i drugim pravnim licima. Poslovne banke mogu koristiti usluge pravnih lica u domenu usluge informisanja (pozivni centri, slanje pošte i sl.) da bi lakše stupili u kontakt sa klijentima fizičkim licima koji imaju problem u otplati, ali im ne mogu ustupati svoja potraživanja.

\section{ZAKLJUČAK}

Analizom tendencija rasta vrednosti problematičnih kredita stanovništvu u Srbiji i njihovog učešća u ukupnom obimu kredita stanovništva potvrđena je hipoteza da rast njihovog obima i učešća u strukturi ukupnih kredita nije dramatičan, ali da je kao tendencija neprihvatljiv, te je neophodno preduzeti mere na makro i nivou pojedinačne banke kako bi se to zaustavilo.

U pogledu faktora koji su uticali na njihovu pojavu i rast, može se izvesti zaključak da su povećanju NPL-a doprinela smanjena kreditna sposobnost fizičkih lica usled smanjenja standarda stanovništva, povećane nesigurnosti poslovanja i nesigurnosti radnog mesta i prilagođavanje metodologije obračuna kreditne sposobnosti klijenata.

Povećanje NPL ima negativan uticaj na bilanse banka i značajan uticaj na poslovnu politiku i strategije banaka koje posluju na domaćem bankarskom tržištu. Realno je očekivati da u narednom periodu banke pooštre kreditne kriterijume za odobrenje retail kreditnih zajmova, što će implicirati da pojedine banke svoj finansijski potencijal preusmere u druge tržišne segmente. Potrebna su sistemska i sveobuhvatna rešenja kako bi se predupredio dalji rast NPL-a, kako u retail, tako i u drugim segmentima, i sistemsko rešavanje postojećeg portfolija problematičnih kredita.

\section{LITERATURA}

International Monetary Fund. (2005). The Treatment of Nonperforming Loans. Preuzeto 15 januara 2015. sa https://www. imf.org/external/pubs/ft/bop/2005/05-29.pdf

Jovanić, T. (2004). Potrošački kredit, pravno-ekonomski aspekti. Beograd: Udruženje banaka Srbije.

Narodna banka Srbije. (2014). Bankarski sektor u Srbiji, kvartalni izveštaji za 2011,2012, 2013. i 2014. godinu. Preuzeto 15 januara 2015. sa http://www.nbs.rs/internet/latinica/55/55_4/

Narodna banka Srbije. (2014). Statistički bilten 2014. Preuzeto 15 januara 2015. sa http://www.nbs.rs/internet/cirilica/90/ sb.html

Republički zavod za statistiku. (2014). Mesečni statistički bilten 12/2014. Preuzeto 11 marta 2015. sa http://webrzs.stat.gov. rs/

Republički zavod za statistiku. (2014). Stopa nezaposlenosti. Preuzeto 5 marta 2015. sa http://webrzs.stat.gov.rs/WebSite/ Public/PageView.aspx?pKey=2;

Rouse, C. N. (1989). Bankers' lending techniques. London: Bankers Books.

Službeni glasnik Republike Srbije. (2014). Odluka o klasifikaciji bilansne aktive i vanbilansnih stavki banke. Preuzeto $15 \mathrm{ja}-$ nuara 2015. sa http://www.paragraf.rs/propisi/odluka_o_ klasifikaciji_bilansne_aktive_i_vanbilansnih_stavki_banke. html

Službeni glasnik Republike Srbije. (2014). Zakon o zaštiti korisnika finansijskih usluga. Sl. glasnik RS 36/2011, 139/2014. 